\title{
Experimental and numerical investigation of water-surface characteristics at crossing connected non-orthogonally to four flat channels
}

\author{
Yong-Wook Jeong ${ }^{1}$, Woochang Jeong ${ }^{2 *}$ \\ ${ }^{1}$ Department of Architecture, Sejong University, 209, Neungdong-ro, Gwangjin-gu, Seoul, Republic of Korea. E-mail: yjeong@sejong.ac.kr \\ 2 Department of Civil Engineering, Kyungnam University, 7, Kyungnamdaehak-ro, Masanhappo-gu, Changwon, Republic of Korea. \\ ${ }^{*}$ Corresponding author. Tel.: +82-55-249-2614. E-mail: jeongwc@kyungnam.ac.kr
}

\begin{abstract}
Most studies on the flood flow characteristics at a crossing focus on channels connected orthogonally or at right angle, but studies on non-orthogonally connected channels remain limited. In this study, hydraulic-model experiments and numerical simulations are performed to analyze the characteristics of the water-surface variation in and around a crossing connected non-orthogonally to four flat channels. Comparison of the measured and simulated water depth distributions in and around the crossing indicates that the results are in relatively good agreement. In the experiment where the angle between two upstream channels is $45^{\circ}$, the water flow pattern in and around the crossing corresponds approximately to Type I proposed by Mignot et al. (2008). However, it was found that there is no any flow type to correspond to the water flow pattern measured in the case of the angle of $135^{\circ}$. For analyzing the variation of the water depth in and around the crossing with inflow, numerical simulation is performed by setting the inflow ratio of the two inlet channels to one, three, and six, respectively.
\end{abstract}

Keywords: Hydraulic-model experiment; Non-orthogonal crossing; Free-surface flow; Water-surface variation.

\section{INTRODUCTION}

In most cities, crossroads connect three or four roads either orthogonally or non-orthogonally, as shown in Figure 1 (a). In general, when the flood entering a crossroad is relatively less and the road gradient is not steep, the flow in a crossroad is characteristically subcritical. However, complex flood flow involving subcritical as well as supercritical flows can also be observed, as shown in Figure 1 (b).

Most of the existing studies on urban flooding have adopted experimental or numerical methods that mainly consider road networks as water channels, instead of observing the actual flood flows moving through roads distributed across urban areas. For example, Best and Reid (1984), Weber et al. (2001), and Neary et al. (1999) experimentally studied the flow characteristics around a crossing connected to three channels under the subcritical conditions. These studies primarily analyzed the flow structure at a crossing, such as recirculation flow, two-dimensional flow, and flow separation and contraction. Bowers (1966) suggested that hydraulic jumps develop in the inflow channels of a crossing under supercritical conditions depending on the geometric shape of the crossing and the water inflow. Schwalt and Hager (1995) conducted a study to identify the major characteristics of surface profiles formed when supercritical flows develop at a crossing connected to three channels. Rivière and Perkins (2004) examined the characteristics of supercritical flows at a crossing to which three channels are connected at $90^{\circ}$, and Rivière et al. (2011) investigated experimentally subcritical flow in an intersection formed by four similar orthogonal channels with two inflows and two outflows for a wide range of experimental conditions. Nania et al. (2004) investigated the characteristics of supercritical flows at a crossing with two inflowing channels and two outflowing channels connected at a right angle, and divided the flows into two types according to the location of hydraulic jumps (Type I for a normal hydraulic jump at each inflowing channel; Type II for a normal hydraulic jump at either inflowing channel and an oblique hydraulic jump within the crossing). Mignot et al. (2008) conducted an experimental and numerical studies on the supercritical flow characteristics

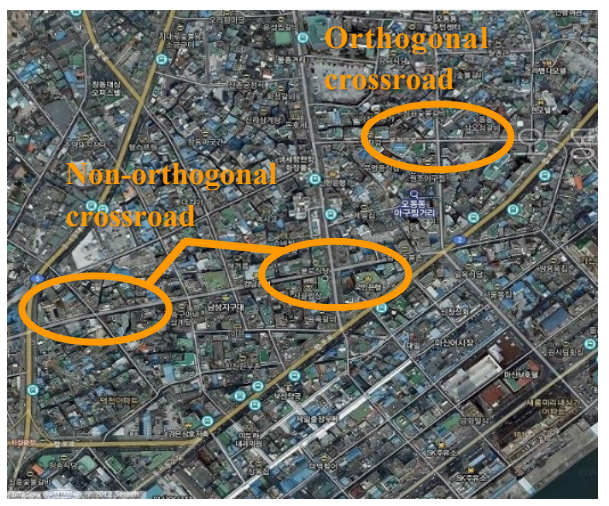

(a)

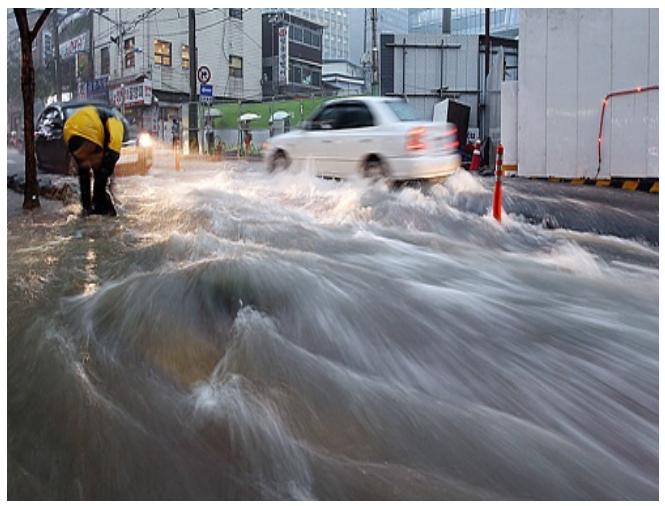

(b)

Fig. 1. (a) Road network in an urban area and (b) complex flood flow at the crossroad. 

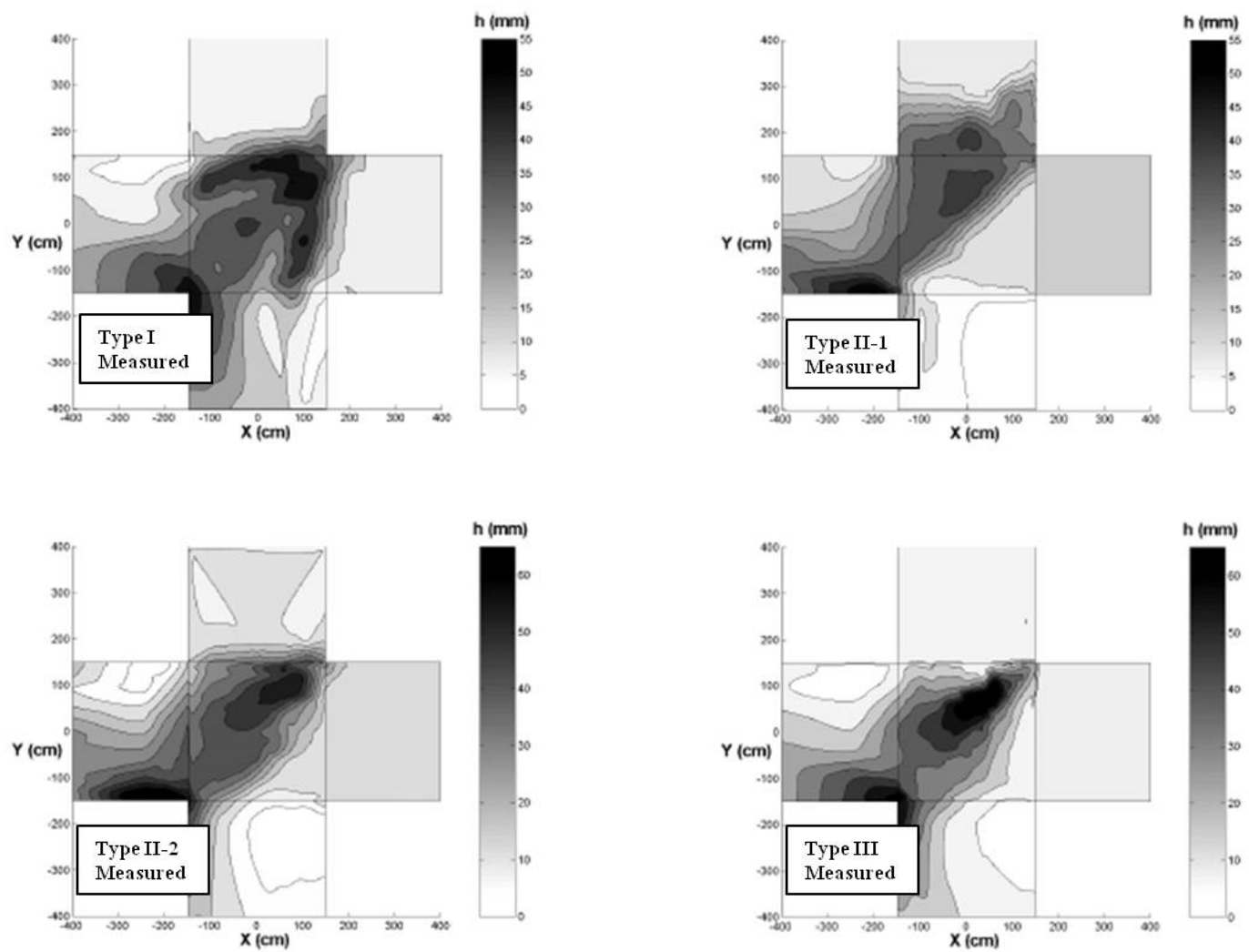

Fig. 2. Water-depth distributions within and around a confluence for four flow types (Mignot et al., 2008).

in and around a crossing where four oblique channels are connected to each other at a right angle, and accordingly divided the flows into four types (Types I, II-1, II-2, and III) based on the location of normal hydraulic jumps formed at inflowing channels, and oblique hydraulic jumps formed within the intersection (Figure 2).

The study's applicability was also verified through a comparison of the experimental results and a simulation in and around the crossing with Rubar 20 (Mignot, 2005; Paquier, 1995), a two-dimensional finite volume model based on the shallow water equation and second-order MUSCL technique. Abderrezzak et al. (2011) conducted an experimental study to investigate the characteristics of dividing critical flows in a $90^{\circ}$ open-channel junction formed by three horizontal equal-width channels, and found a relationship between the discharge division ratio and the tailwater Froude number. Recently, Rivière et al. (2014) examined experimentally trans-critical flows in three and four channel intersections and proposed empirical correlations derived from the experimental data for the flow distribution in three-channel intersections and four-channels intersections with one or two critical sections.

Shetter and Murthy (1996) numerically analyzed the flow characteristics at a crossing connected to three channels under the subcritical conditions using a two-dimensional numerical model based on the $k-\mathcal{E}$ turbulence technique and shallow water equation. In addition, Khan et al. (2000) applied a simple turbulence model, based on the mixing length formula, and the two-dimensional model, based on the shallow water equation, for numerically analyzing the flow characteristics at a bifurcation and a confluence of three channels under the subcritical condition. To verify applicability to subcritical conditions at a confluence, Huang et al. (2002) used the three-dimensional model based on the $k-\mathcal{E}$ turbulence technique for comparative analysis with the experimental results of Shumate (1998).
Ghostine et al. (2009) utilized the experimental results reported by Mignot et al. (2006) to verify the applicability of the twodimensional finite element model based on the Runge-Kutta Discontinuous Galerkin (RKDG) technique by comparing the simulation results from Rubar 20 and FLUENT, a threedimensional model. Jeong et al. (2010) recently numerically analyzed on the flood flow characteristics at a crossing symmetrically connected to four channels using the twodimensional well-balanced HLLC finite volume model. Very recently, Mignot et al. (2019) reviewed the 45 existing studies available on urban flooding based on laboratory experiments to help computational and laboratory modelers.

As apparent, most studies on the flood flow characteristics at a crossing focus on channels connected orthogonally or at right angle, but studies on non-orthogonally connected channels remains limited. In this study, a hydraulic-model experiment and a numerical simulation using ANSYS (2013), which is the commercial three-dimensional CFD model, are performed for investigating the characteristics of water-surface variation in and around a crossing connected non-orthogonally to four channels. The simulated results are verified by comparison with the results of the hydraulic-model experiment, and the flow characteristics at a crossing are analyzed under various inflow scenarios.

\section{HYDRAULIC-MODEL EXPERIMENT \\ 2.1 Experimental methods and conditions}

A hydraulic model was used to analyze the flood flow characteristics of channels and a crossing composed of acrylic as shown in Figure 3, in order to observe the water flow and includes a pump to provide water flow and an electronic flowmeter installed between the water tanks connected to the end of each channel for controlling the flow. 


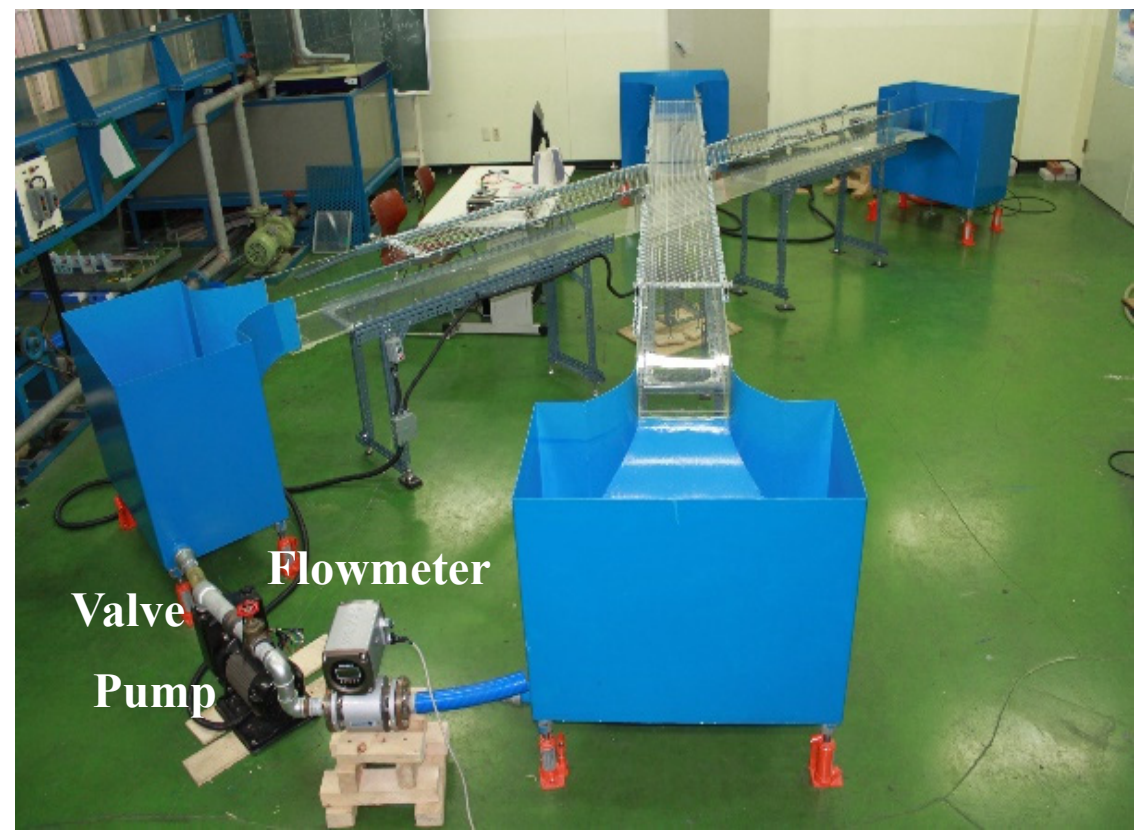

Fig. 3. Set-up of the hydraulic-experiment model.
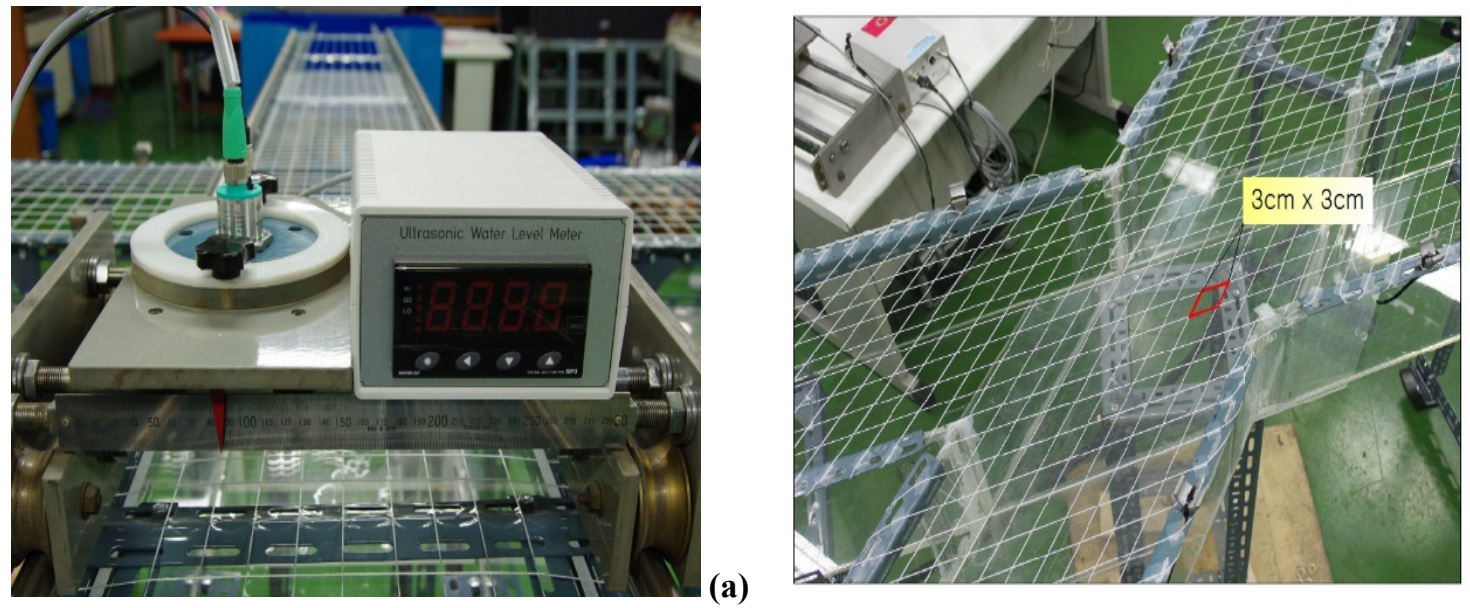

(b)

Fig. 4. (a) Ultrasound water level meter and (b) Grid system around a crossing.

Flow control valves and electronic flowmeters (WTM-1000, range: $0.03 \sim 10 \mathrm{~m}^{3} / \mathrm{s}$, accuracy: $\pm 0.5 \%$ and repeatability: $\leq 0.1 \%$ ) were used to control the water flow and generate flow into the channels. Then, after the flows were stabilized (within approximately $50 \mathrm{~s}$ in this experiment), the ultrasound water level meter (UC500-20GM, range: 0.838 to $30.480 \mathrm{~cm}$, accuracy: better than $0.2 \%$ of range) shown in Figure 4 (a) was used to measure the water depth within a series of the grids around the crossing. The grid system included 1,447 $(3 \mathrm{~cm} \times 3$ $\mathrm{cm}$ ) diamond shape grids, as illustrated in Figure 4 (b). After the water flow in the crossing and channels reaches steady state, the water depth was measured 5 times for each grid and its values presented hereafter are the average of 5 measurements.

The widths of the four channels connected to the crossing were identical $0.3 \mathrm{~m}$ each. The lengths of the two horizontally connected channels were $2.0 \mathrm{~m}$ each, and those of the two channels connected non-orthogonally at an inclination of $45^{\circ}$ to the horizontal channels were $2.3 \mathrm{~m}$ each.

In Figure 5, (1), 2), (3) and (4) represent the channels connected in the crossing. Two cases were considered in the experiment. In Case I, channels (1) and (2) were the inflow channels and the angle between two upstream channels was $45^{\circ}$; channels (3) and (4) were the outflow channels (Figure 5 (a)). In Case II, channels (1) and (4) were the inflow channels and the angle between two upstream channels was $135^{\circ}$; channels (2) and (3) are the outflow channels (Figure 5 (b)).

$Q_{1}$ and $Q_{2}$ are the inflows at the inflow channel boundaries, and $h_{1}$ and $h_{2}$ refer to the water depths corresponding to each inflow channel boundary. $Q_{3}$ and $Q_{4}$ are the outflows through the outflow channel boundaries, and $h_{3}$ and $h_{4}$ are the water depth corresponding to each outflow channel boundary.

At the beginning of the experiment, there is no water flow in all channels. When the water-surface in the water tank connected to the inflow channel reaches the bottom of the inflow channel, the water starts to flow in the inflow channel. The inflow was controlled by the electronic flowmeter connected to the water tank and the water depth at the inflow channel boundary was measured by an attached ruler. The outflow was measured by considering the volume of water filled $\left(\Delta \mathrm{V}=l \times w \times h_{2}-l \times w \times h_{1}\right)$ ( $l$ and $w$ are the length and width of water tank, respectively) in the water tanks for a given time interval $\left(t_{2}-t_{1}\right)$ (Figure 6). 


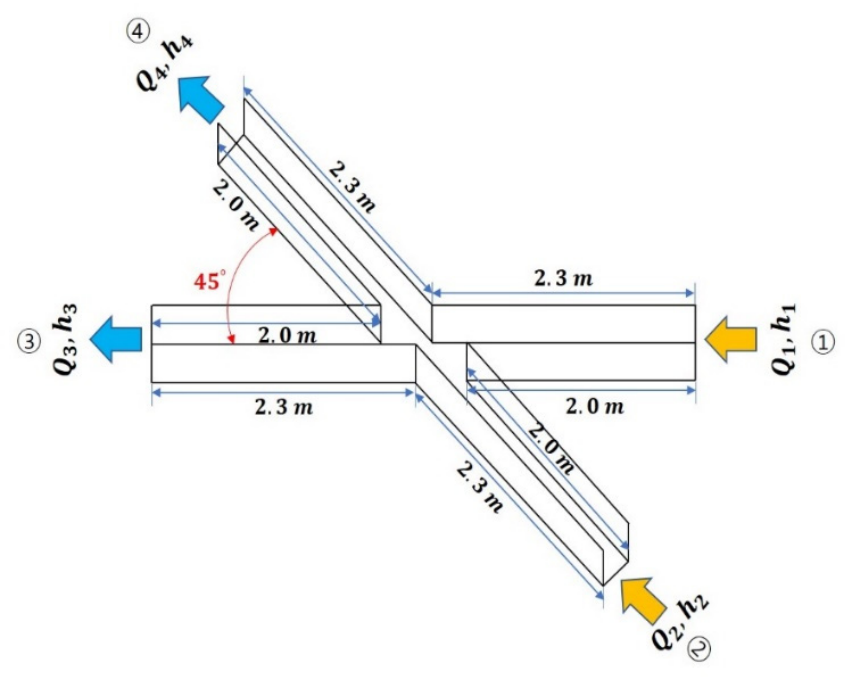

(a)

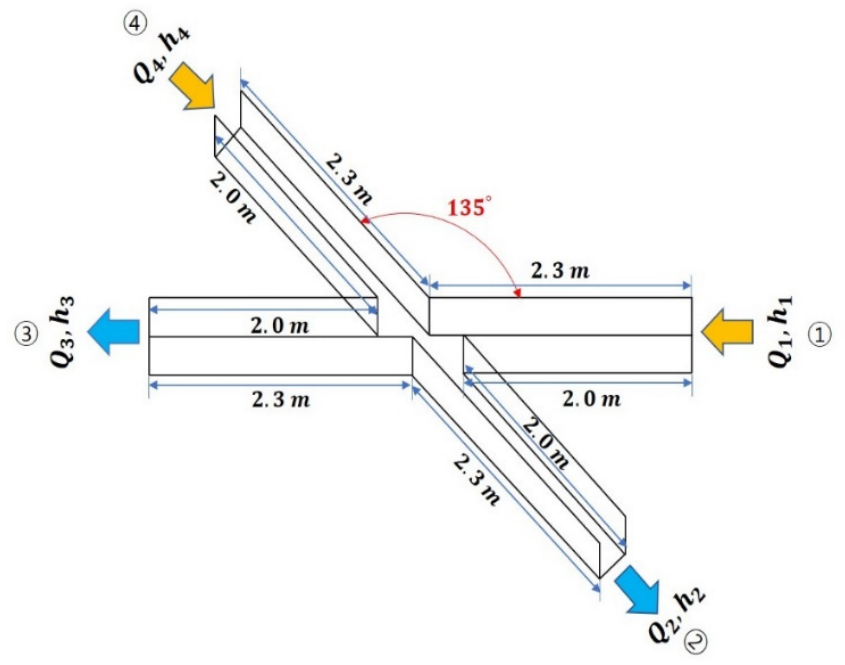

(b)

Fig. 5. Experimental conditions: (a) Case I and (b) Case II.

Table 1 summarizes the inflow conditions in the two inflow channels and the corresponding water depths for each case. In this study, the experiment was conducted by setting the inflows ratio of the two inflow channels to one (flow ratio $=1$ ) and three (flow ratio $=3$ ).

\subsection{Experimental results and analyses}

Figure 7 depicts the spatial variation of water depth measured around the crossing for Case I after the flow reaches steadystate. In Case I-1, the water flowing through the two inflow channels approaches the crossing with a depth of $3.1 \mathrm{~cm}$. After

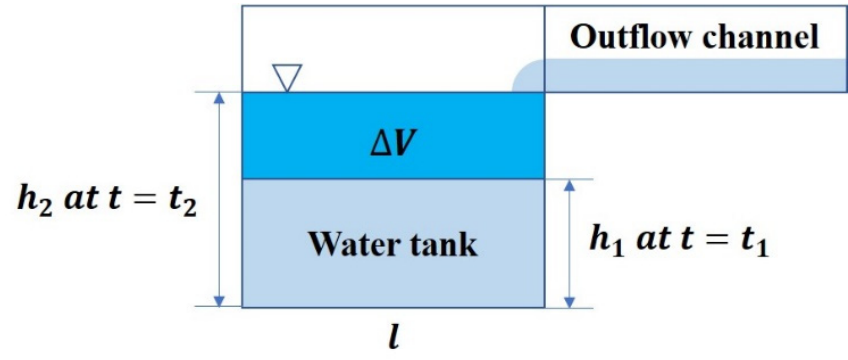

Fig. 6. Schematic illustration of outflow calculation.

flowing into the crossing, the water depth begins to decrease, with the depth around the mouth of channels (3) and (4) connected to the crossing decreasing to an average of $1.0 \mathrm{~cm}$. When the water into the crossing reaches at the point adjoining channels (3) and (4) meet (•), the flow is separated and an oblique hydraulic jump is appeared. This type of water flow around the crossing corresponds approximately to Type I proposed by Mignot et al. (2008).

For Case I-2, after flowing through channel (1) at a depth of $5.0 \mathrm{~cm}$ and channel (2) at a depth of $3.2 \mathrm{~cm}$, the water flows into the crossing with a significantly lower depths of $1.0 \mathrm{~cm}$ and $1.4 \mathrm{~cm}$ at the exits of the channels (3) and (4), respectively (Figure 6.I-1). After the flow is stabilized, channels (1) and (2) have a similar depth distribution $(5.0 \mathrm{~cm}$ on an average). This result can be attributed to the backwater effect: the larger quantity of water flowing into channel (2) moves faster than that flowing into the channel (1), causing the water flowing through channel (1) to move in a direction opposite to the flow without appropriately passing through the crossing (Figure 6.I-2).

Figure 8 displays the spatial variation of the water depth measured around the crossing for Case II. In Case II-1, the water quantity flowing into channels (1) and (4) is the same at $100 \mathrm{l} / \mathrm{min}$, and the depth of water moving through these two inflowing channels is approximately $3.1 \mathrm{~cm}$ on reaching the crossing. However, the water depth distribution at the crossing in Case II-1 exhibits a considerably different trend from that that of Case I-1. After the water flows into the crossing via the two channels, the water depth does not decrease; instead, it maintains the water depth before inflow. The water flow into the crossing is divided after reaching the point $(\bullet)$ adjoining channels (2) and (3), and moves into each channel with oblique hydraulic jumps. This type of water flow around the crossing does not correspond to any flow type proposed by Mignot et al. (2008). The rapid decrease in the water depth (from 3.1 to 1.7 $\mathrm{cm}$ ) in channels (2) and (3) after passing the crossing adopted a tilted shape because of the continual supply of water from the point of divided flow.

In Case II-2, because of the larger quantity of water in channel (4) flowing toward the crossing at a fast pace, the water flowing into the channel (1) fails to pass the crossing and demonstrates the backwater effect, as observed in Case I-2, with the water moving toward the flow direction. The water

Table 1. Inflow conditions for cases I and II (1), (2), and (4): channel number).

\begin{tabular}{cccccc}
\hline Case I- & $\left.Q_{1}(1)\right)(1 / \mathrm{min})$ & $h_{1}(\mathrm{~m})$ & $Q_{2}($ (2) $)(1 / \mathrm{min})$ & $h_{2}(\mathrm{~m})$ & $Q_{2} / Q_{1}$ \\
\hline 1 & 100 & 0.0209 & 100 & 0.0209 & 1.0 \\
2 & 100 & 0.0209 & 300 & 0.0404 & 3.0 \\
\hline Case II- & $Q_{1}(1)(1 / \mathrm{min})$ & $h_{1}(\mathrm{~m})$ & $\left.Q_{4}(4)\right)(1 / \mathrm{min})$ & $h_{4}(\mathrm{~m})$ & $Q_{4} / Q_{1}$ \\
\hline 1 & 100 & 0.0209 & 100 & 0.0209 & 1.0 \\
2 & 100 & 0.0209 & 300 & 0.0404 & 3.0 \\
\hline
\end{tabular}




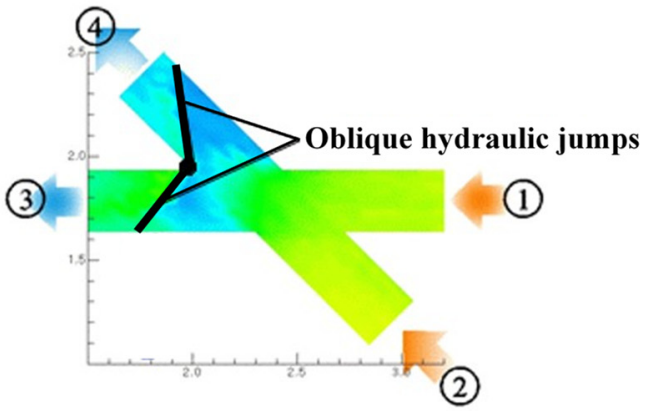

I-1

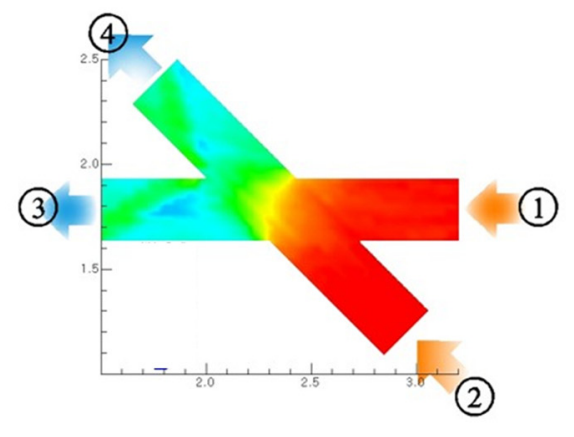

Water depth [m]
\[ \begin{array}{l}0.060 \\ 0.044 \\ 0.038 \\ 0.031 \\ 0.026 \\ 0.019 \\ 0.013 \\ 0.006 \\ 0.000\end{array} \]

Fig. 7. Spatial variation of water depth around the crossing: Case I.

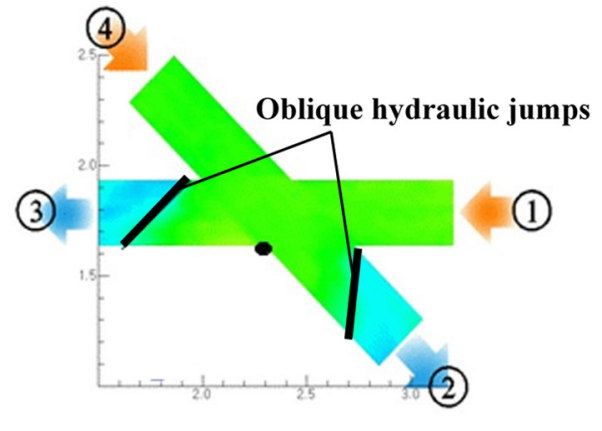

II-1

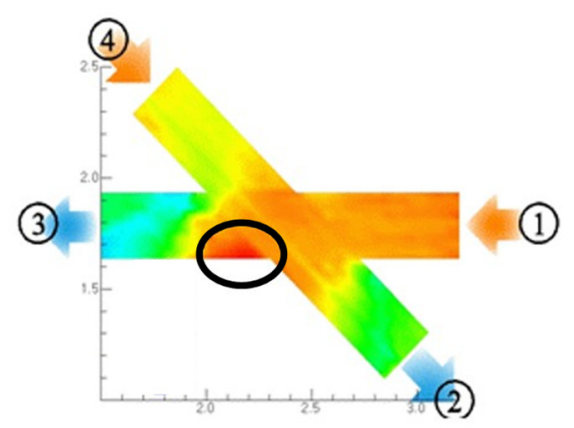

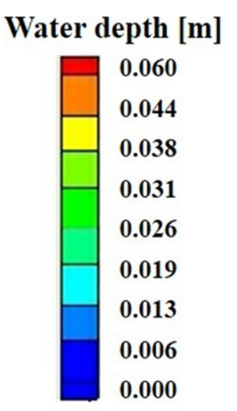

Fig. 8. Spatial variation of water depth around the crossing: Case II.

II-2

Table 2. Comparison of inflow and outflow measured in the experiment.

\begin{tabular}{|c|c|c|c|c|c|c|c|}
\hline \multirow{2}{*}{ Case I- } & \multicolumn{3}{|c|}{ Inflow (1/min) } & \multicolumn{3}{|c|}{ Outflow (1/min) } & \multirow{2}{*}{$\begin{array}{l}\text { Absolute error } \\
\qquad \begin{array}{l}\text { (1/min) } \\
\text { (a)-(b) })\end{array}\end{array}$} \\
\hline & $Q_{1}$ & $Q_{2}$ & $Q_{1}+Q_{2}$ (@) & $Q_{3}$ & $Q_{4}$ & $Q_{3}+Q_{4}$ (b) & \\
\hline 1 & 100 & 100 & 200 & 99.6 & 100.2 & 199.8 & 0.2 \\
\hline 2 & 100 & 300 & 400 & 189.0 & 211.2 & 400.2 & 0.2 \\
\hline \multirow{2}{*}{ Case II- } & \multicolumn{3}{|c|}{ Inflow (1/min) } & \multicolumn{3}{|c|}{ Outflow (1/min) } & Absolute error \\
\hline & $Q_{1}$ & $Q_{4}$ & $Q_{1}+Q_{4}$ (@) & $Q_{3}$ & $Q_{2}$ & $Q_{3}+Q_{2}$ (b) & (a)-(b) \\
\hline 1 & 100 & 100 & 200 & 99.6 & 100.2 & 199.8 & 0.2 \\
\hline 2 & 100 & 300 & 400 & 161.4 & 237.6 & 399.0 & 0.1 \\
\hline
\end{tabular}

depth distribution is observed to be greater in channel (1) with the reduced inflow compared to channel (4) with a greater inflow at the initial stage. In Case I-2, the inflow to channels (1) and (2) is from the same direction $\left(45^{\circ}\right)$, but in Case II-2, the direction of inflow into channels (1) and (4) is almost opposite directions $\left(135^{\circ}\right.$ apart). This causes greater disturbance in the flows at the crossing, and thereby, a greater water depth distribution. The flow at the crossing heads toward channel (1) with a relatively lesser water quantity, contributing to greater water depth. In addition, in Case I-2, an area with rapidly increasing water depth (the area marked with an oval) in channel (3) in the immediate vicinity of the crossing is not observed.

Further, the results of the hydraulic-model experiments for Cases I and II are verified through numerical simulation, and the results are described in Section 3. Table 2 shows the comparison between inflows and outflows based on the results of the hydraulic-model experiment for Cases I and II; the inflow and outflow agree relatively well in both cases.

\section{NUMERICAL SIMULATIONS 3.1 ANSYS CFX model}

For the homogenous mixture of multiphase flows, such as a flow moving through an open channel with a mixture of air and water in a rectangular coordinate system, ANSYS CFX commercial model (ANSYS, 2013) was applied in this study. This model has been widely applied to simulate various types of water flow in open channels, such as flow around a halfsubmerged cylinder in an open channel (Alamayreh et al., 2021), energy loss in steep open channels (Thappeta et al., 2021), design of contractions in supercritical flow open channels (Martinez and Niño, 2020). The numerical scheme of this model is the finite volume method, which divides the computational domain inti small cells for obtaining solutions by assigning a boundary condition to each cell, and the complete set of governing equations for an incompressible multiphase flow model is as follows: 
Continuity equation

$\frac{\partial \rho_{m}}{\partial t}+\nabla \cdot\left(\rho_{m} \overrightarrow{\mathrm{V}}_{\mathrm{m}}\right)=0$

Momentum equation

$\frac{\partial\left(\rho_{m} \overrightarrow{\mathrm{V}}_{\mathrm{m}}\right)}{\partial t}+\nabla \cdot\left(\rho_{m} \overrightarrow{\mathrm{V}}_{\mathrm{m}} \otimes \overrightarrow{\mathrm{V}}_{\mathrm{m}}\right)=-\nabla p_{m}+\nabla \cdot\left(\overline{\bar{\tau}}+\overline{\bar{\tau}}_{\mathrm{t}}\right)+\overrightarrow{\mathrm{f}}$

Volume fraction transport equation

$\frac{\partial\left(\alpha_{l} \rho_{l}\right)}{\partial t}+\nabla \cdot\left(\alpha_{l} \rho_{l} \overrightarrow{\mathrm{V}}_{\mathrm{m}}\right)=0$

where, $\rho_{m}$ is the mixture density of the fluid, $\overrightarrow{\mathrm{V}}_{\mathrm{m}}=[u, v, w]$ is the velocity vector, $t$ is the time, $p_{m}$ is the pressure, $\overline{\bar{\tau}}$ is the viscous stress tensor, $\overline{\bar{\tau}}_{t}$ is the turbulence viscous stress tensor, $\vec{f}$ is an external force such as buoyancy, $\rho_{l}$ is the density of each fluid in the mixture and $\alpha_{l}$ is the liquid-phase volume fraction ranging between $[0,1]$ for each liquid phase. If water and air are mixed, the value of $\alpha_{l}$ becomes 0.5 at the boundary between the two fluids. If two fluids, such as water and air, are mixed with each other, the mixture density $\rho_{l}=\sum_{n=1}^{2} \alpha_{n} \rho_{m}$.

The numerical analysis methods provided by the ANSYS CFX model for analyzing the turbulence elements include the Reynolds-Averaged Navier-Stokes (RANS), Eddy-Viscosity method, RANS Reynolds-Stress method, and Eddy Simulation method (ANSYS Inc., 2013). In this study, the standard $k-\varepsilon$ model, which is a type of RANS Eddy-Viscosity method, was chosen due to its simplicity in terms of its empirical parameters and its wide use in engineering applications (Matthews et al., 1998).

\subsection{Model verification}

For verifying the model applied in this study, the four different inflow conditions in Case I and II of the hydraulic-model experiments were simulated under an unsteady state condition in order to investigate the spatial variation of the water depth with time. The channels were presumed to be flat and without inclination; the grid system comprised 153,304 nodes and 621,634 cells. The cell type was tetrahedron and the maximum, minimum, and mean cell sizes were $4.5 \times 10^{-7}, 2.4 \times 10^{-7}$, and $3.8 \times 10^{-7} \mathrm{~m}^{3}$, respectively. The upstream boundaries of the two inflow channels (1) and (2) for Case I, and channels (1) and (4) for Case II in Figure 4 were considered as the inflow boundary conditions. The downstream boundaries of the two outflow channels (1) and (4) for Case I, and channels (2) and (3) for Case II in Figure 4 were considered as the open boundary conditions. In addition, the channel bottoms and side-walls were presumed to be flat and smooth. The downstream boundaries of the outflow channels were treated as open boundary condition. The total simulation time was set to $60 \mathrm{~s}$, which is sufficient to reach steady state, and the time interval was set to $0.01 \mathrm{~s}$. In this verification, the roughness of the bottom and side walls in all channels was ignored because it was assumed that the acrylic surface is very smooth.

Table 3 compares the outflows $Q_{3 M}$ and $Q_{4 M}$ measured at the downstream boundaries of the channels in Case I and the outflows $Q_{2 M}$ and $Q_{3 M}$ in Case II, respectively, and the simulated outflows are $Q_{3 S}$ and $Q_{4 S}$ in Case I and $Q_{2 S}$ and $Q_{3 S}$ in Case II, respectively. The simulated and measured values for each outflow condition show considerable agreement.

Figures 9 and 10 compare the measured and simulated results of the change in the water depth spatially along the centerline of the four channels around the crossing, for Cases I and II (simulation time of $60 \mathrm{~s}$ ). The results demonstrate that the spatial variation of the simulated water depth generally agrees with that the measured results. A significant difference in the water depth between Case I and Case II is observed: the flow moving from channel (1) to channel (3) in Case I exhibits a drastic decrease in the water depth in the crossing and a rapid increase in the water depth, similar to a hydraulic jump, after passing the crossing; however, in Case II, the water depth maintains its previous depth within the crossing, reduces rapidly after passing through the crossing, and then begins to slowly increase.

For a more quantitative comparison of the measured and simulated water depths, the three error equations (4), (5), and (6) involving $L_{1}$ (absolute mean error), $L_{2}$ (root mean square error), and $L_{\infty}$ (maximum error), respectively, were applied. The estimated results are depicted in Table 4. As the results from these three error equations show significantly small values, it can be concluded that the results of the numerical model applied in this study are in agreement with the measured values.

$$
\begin{aligned}
& \|e\|_{L_{1}}=\frac{1}{n}\left(\frac{1}{h_{\max }} \sum_{i-1}^{n}\left|\epsilon_{i, j}\right|\right) \\
& \|e\|_{L_{2}}=\left[\frac{1}{n}\left(\frac{1}{h_{\max }^{2}} \sum_{i-1}^{n}\left|\epsilon_{i, j}\right|^{2}\right)\right]^{1 / 2} \\
& \|e\|_{L_{\infty}}=\frac{1}{h_{\max }}\left|\epsilon_{i, j}\right|
\end{aligned}
$$

\section{CHANGES IN WATER DEPTH AT THE CROSSING WITH INCREASING INFLOWS}

For analyzing the changes in the water depth in and around the crossing with increased inflow, the results of Cases I-1, I-2, II-1, and II-2 are compared with those of the numerical simulation by setting the ratio between the inflow into the channels (Cases I-3 and II-3) to six (inflow ratio $=6$ ). The numerical simulation results alone were used for comparative analysis because the electronic flowmeter adopted for the hydraulicmodel experiments, it is possible to adjust the inflow only up to $450 \mathrm{l} / \mathrm{min}$, rendering it impossible to perform experiments that require an inflow ratio of six. The inflow conditions for Cases I-3 and II-3 are shown in Table 5.

Table 3. Comparison of outflows measured and simulated at two downstream channels boundaries.

\begin{tabular}{ccccc}
\hline \multirow{2}{*}{ Case I- } & \multicolumn{2}{c}{ Measured (1/min) } & \multicolumn{2}{c}{ Simulated (1/min) } \\
\cline { 2 - 5 } & $Q_{3 M}$ & $Q_{4 M}$ & $Q_{3 S}$ & $Q_{4 S}$ \\
\hline 1 & 99.6 & 100.2 & 99.6 & 99.6 \\
2 & 186.0 & 211.2 & 189.6 & 209.4 \\
\hline \multirow{2}{*}{ Case II- } & \multicolumn{2}{c}{ Measured (1/min) } & $Q_{3 S}$ & Simulated (1/min) \\
\cline { 2 - 5 } & $Q_{2 M}$ & 100.2 & $Q_{3 S}$ & 100.2 \\
2 & 99.6 & 237.6 & 163.8 & 240.6 \\
\hline
\end{tabular}



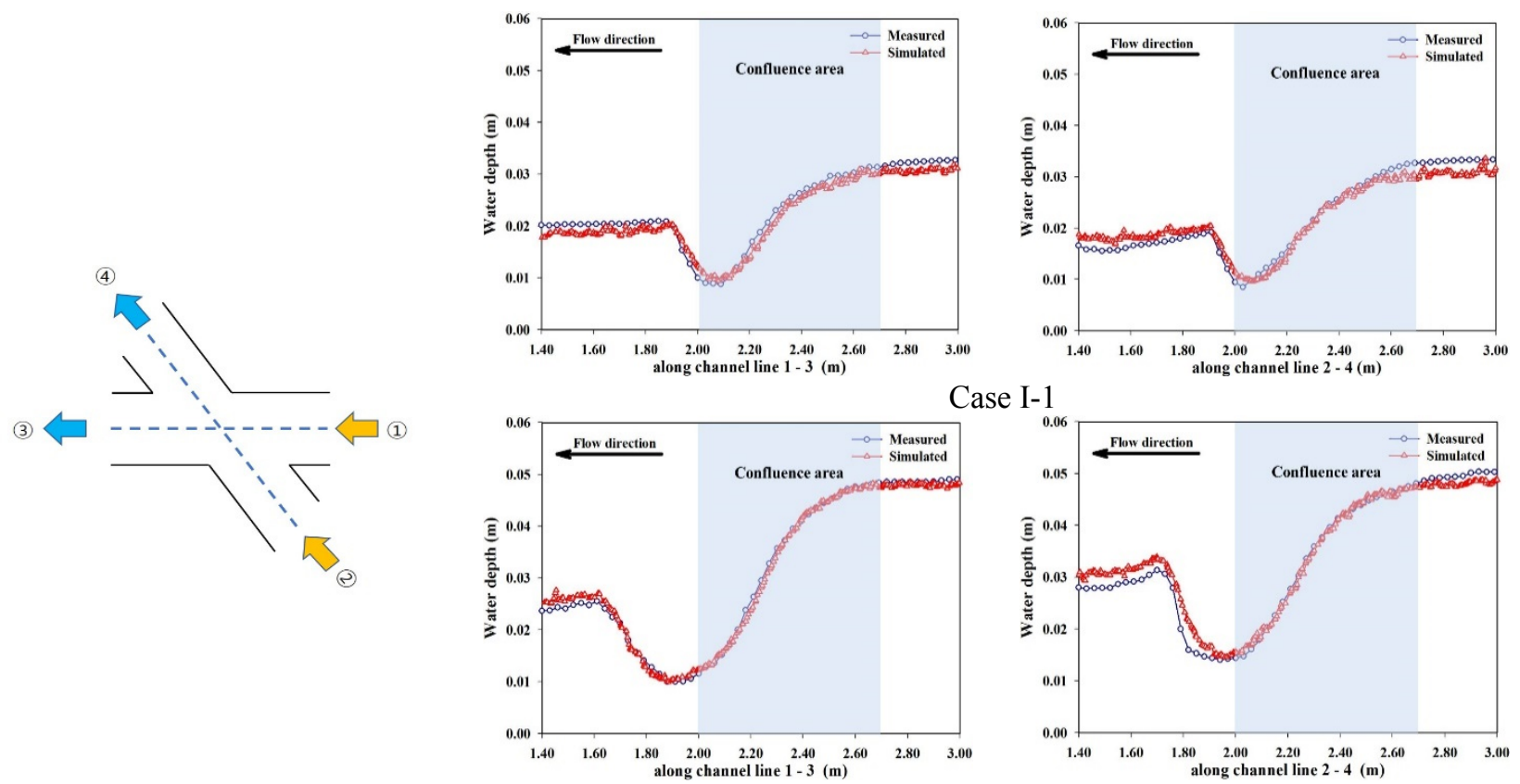

Case I-2

Along Channels (1)-(3)

Along Channels (2)-(4)

Fig. 9. Water-surface profiles along channels for Case I.
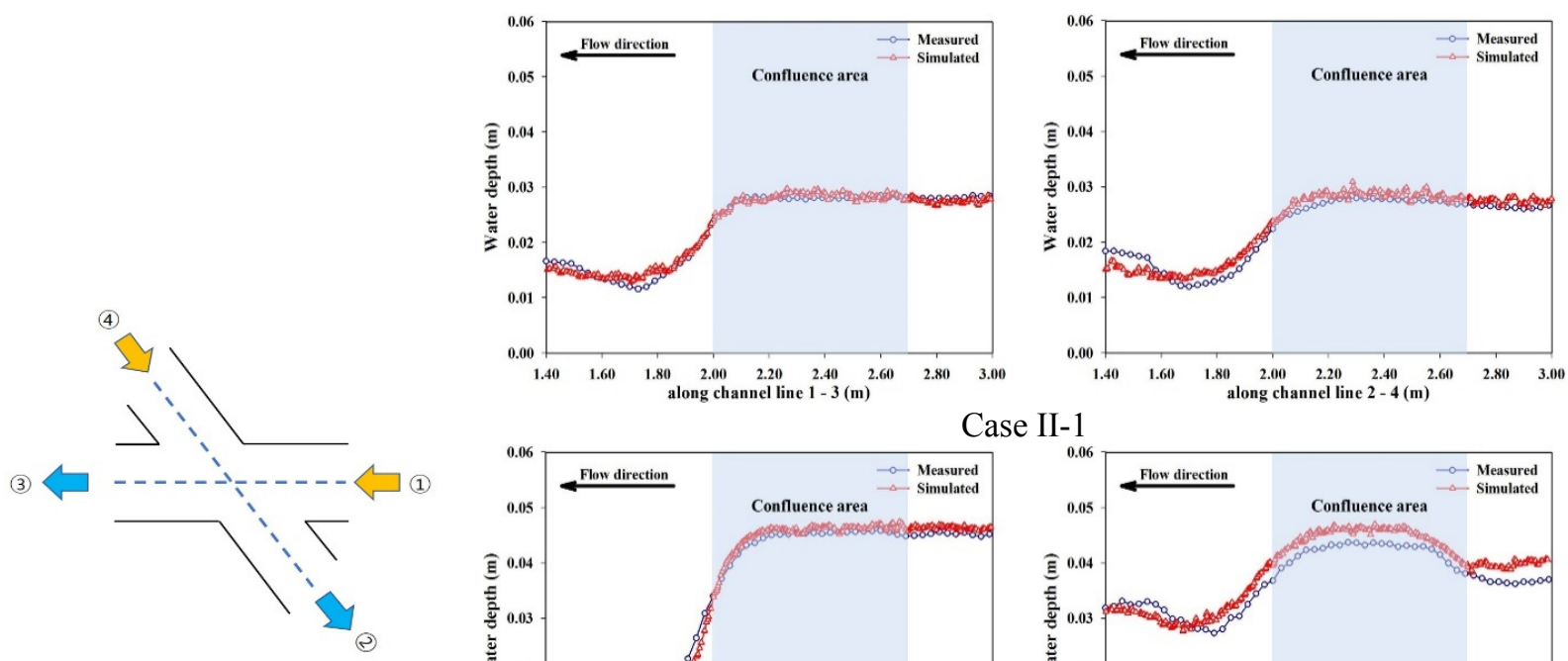

Case II-1
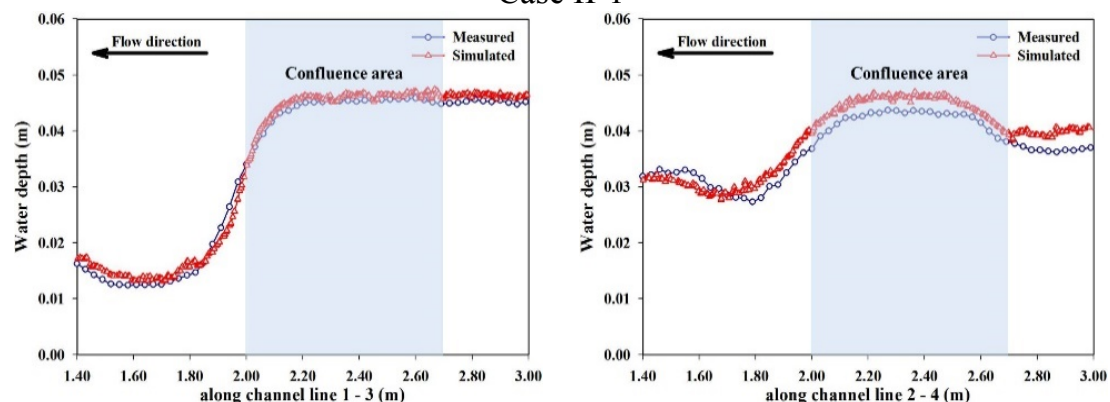

Case II-2

Along Channels (1)-(3)

Fig. 10. Water-surface profiles along channels for Case II.

Along Channels (2)-(4)

Table 4. Comparison of $L_{1}, L_{2}$ and ${ }^{L_{\infty}}$ errors for cases I and II.

\begin{tabular}{ccccccc}
\hline \multirow{2}{*}{ Case } & \multicolumn{3}{c}{ Along channels (1)-(3) } & \multicolumn{3}{c}{ Along channels (2)-(4) } \\
\cline { 2 - 7 } & $L_{1}$ & $L_{2}$ & $L_{\infty}$ & $L_{1}$ & $L_{2}$ & $L_{\infty}$ \\
\hline I-1 & 0.04293 & 0.00221 & 0.07745 & 0.04719 & 0.00306 & 0.12954 \\
I-2 & 0.01306 & 0.00260 & 0.04340 & 0.02678 & 0.00130 & 0.11947 \\
II-1 & 0.02520 & 0.00060 & 0.08472 & 0.04117 & 0.00214 & 0.07703 \\
II-2 & 0.02613 & 0.00085 & 0.07004 & 0.05752 & 0.00352 & 0.09026 \\
\hline
\end{tabular}


Table 5. Inflow conditions for Cases I-3 and II-3 (1), (2) and (4): channel number).

\begin{tabular}{cccc}
\hline Case I- & $Q_{1}(1 / \mathrm{min})$ & $Q_{2}(1 / \mathrm{min})$ & $Q_{1} / Q_{2}$ \\
\hline 3 & 100.0 & 600.0 & 6.0 \\
\hline Case II- & $Q_{1}(1 / \mathrm{min})$ & $Q_{4}(1 / \mathrm{min})$ & $Q_{1} / Q_{4}$ \\
\hline 3 & 100.0 & 600.0 & 6.0 \\
\hline
\end{tabular}

Case I-

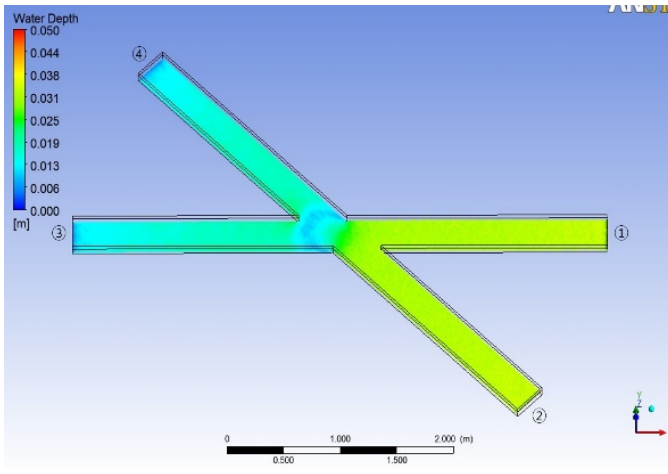

兑
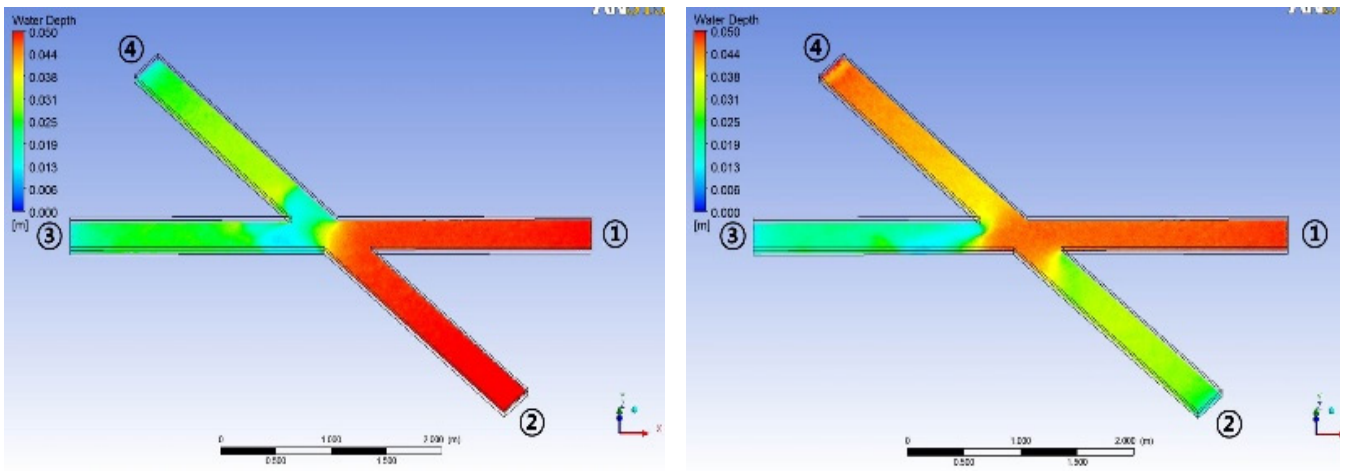

$\stackrel{4}{\longrightarrow}$

2

3

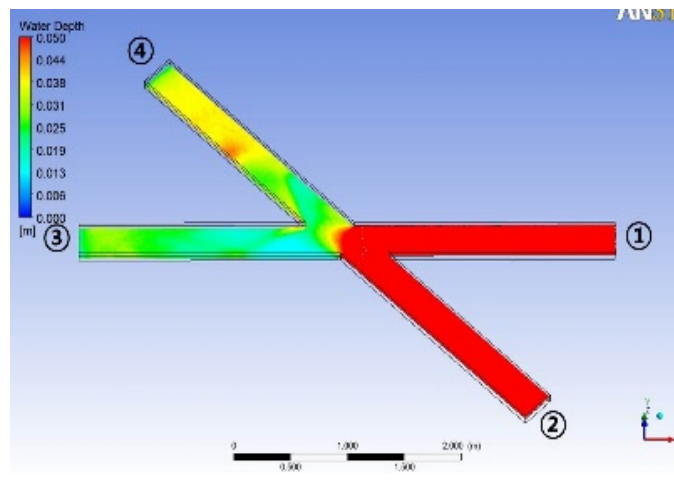

Case II-

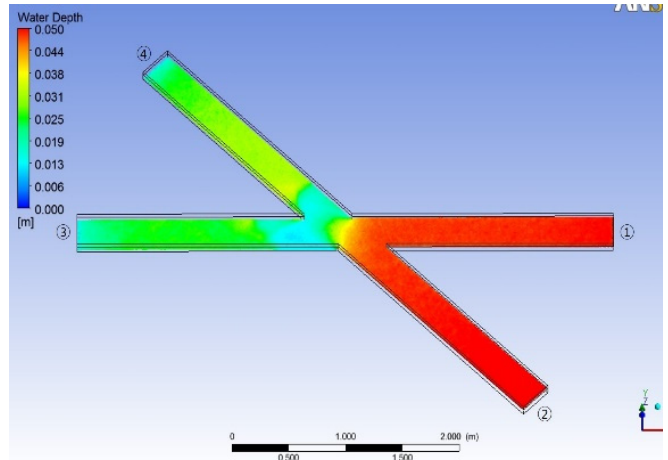

$\underline{\varepsilon}^{\circ}$

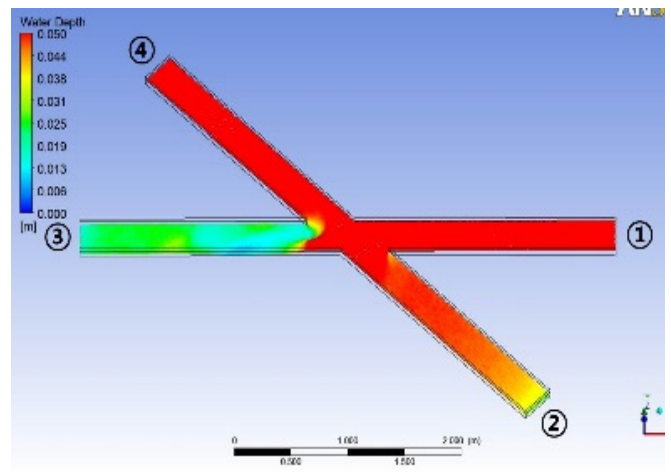

Fig. 11. Comparison of water-surface profiles along channels with increased inflow for Case I and II.

Figure 11 compares the spatial variation of the water depth in Cases I-3 and II-3 at $60 s$ with those in Cases I-1 and -2 and II-1 and -2, respectively. As the inflows increase, the backwater effect in channel (1) is enhanced, and the water depth in Case I increases more in channel (4) than in channel (3). The result is the same for Case II-3: when the inflows increases, the backwater effect strengthens in channel (1), and the water depth increases in channel (2). However, the increase in water depth in channel (3) is relatively limited.

Based on the results shown in Figure 12, the spatially changing water depths along the centerline of each of the four channels around the crossing in Cases I and II are compared, as shown in Figure 11. The water flowing through channels (1) and (3) in Case I enters the crossing with an increased water depth (approximately $3.10 \mathrm{~cm}$ for Case I-1, $4.85 \mathrm{~cm}$ for Case I2, and $6.35 \mathrm{~cm}$ for Case I-3); a rapid decrease in all these water depths occurs in the crossing in Case I. After the water flows through the crossing, a hydraulic jump is observed in Case I-2 farther from the crossing compared to the Case I-1 location (1.93 $\mathrm{m}$ for Case I-1 and $1.63 \mathrm{~m}$ for Case I-2); the scale is greater in Case I-2 $(1.0 \mathrm{~cm}$ for Case I-1 and $1.5 \mathrm{~cm}$ for Case I-2). 

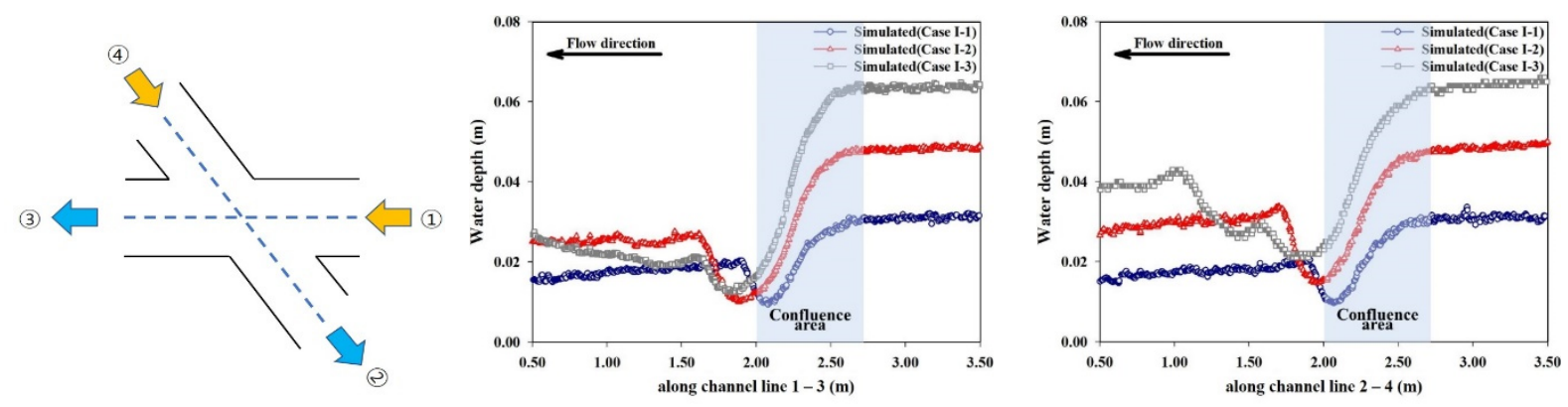

Case I
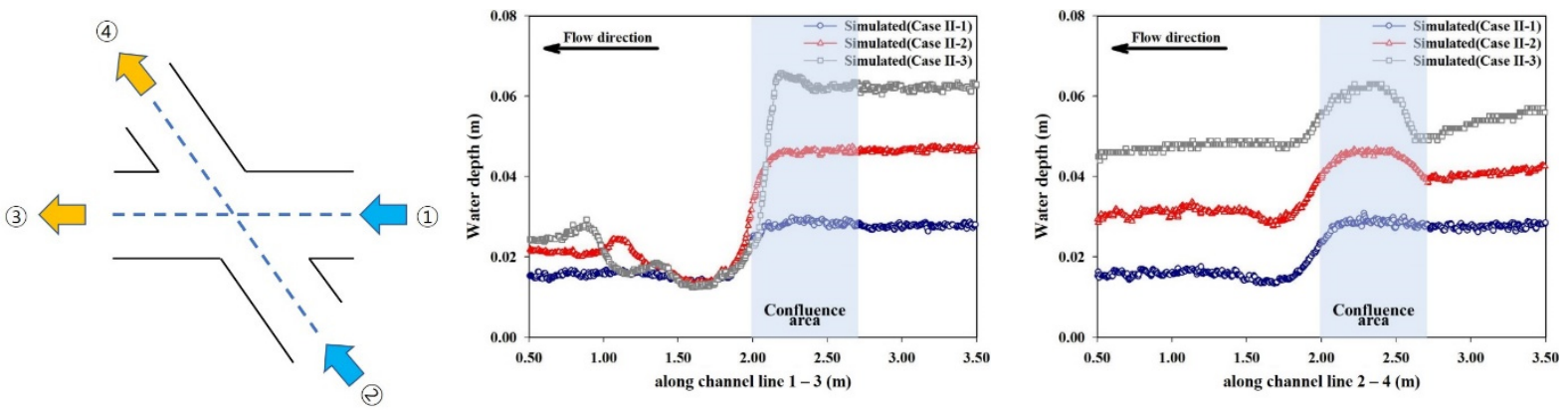

Case II
Along Channels (2)-(4)

Fig. 12. Comparison of water-surface profiles along channels with increased inflow for Cases I and II.

In Case I-3, a smaller hydraulic jump is observed at a location similar to that of the hydraulic jump in Case I-2; however, a location within $0.6 \mathrm{~m}$ is associated with a gradually increasing water depth. As the inflow increases, the water depth in channels (2) and (4) exhibits a clear increasing tendency. The water depth before the arrival of the flow at the crossing and within the crossing increases to a level similar to those in channels (1) and (3).

The decreasing tendency of the water depth differs in the crossing; as the inflow increases, the degree to which the water depth reduces also increases $(3.10 \mathrm{~cm}$ to $1.00 \mathrm{~cm}$ in Case I-1, $4.85 \mathrm{~cm}$ to $1.50 \mathrm{~cm}$ in Case I-2, and $6.35 \mathrm{~cm}$ to $2.35 \mathrm{~cm}$ in Case I-3). After the flow passes the crossing, a hydraulic jump occurs at a location increasingly farther from the crossing when the inflow increases, and there is an increase in the scale as well $(1.0 \mathrm{~cm}$ for Case I-1, $1.5 \mathrm{~cm}$ for Case I-2, and $2.0 \mathrm{~cm}$ for Case I-3). Unlike in Cases I-1 and I-2, two hydraulic jumps are observed in Case I-3, which may contribute to the smaller hydraulic jumps in channels (1) and (3).

In Case II, water flows through channels (1) and (3) reaches the crossing at an increased water depth (the same as in Case I) as the inflow increases. In Cases II-1 and II-2, the water depth in the crossing remains almost constant and rapidly decreases immediately before passing the crossing. Further, the water depth falls to approximately $1.1 \mathrm{~cm}$ before increasing again. Compared to Case I, the scale of the hydraulic jumps is smaller (1.5 cm for Case II- 1 and $3.25 \mathrm{~cm}$ for Case II-2), and they are located farther from the crossing as the inflow increases $(1.35$ $\mathrm{m}$ for Case II-1 and $1.15 \mathrm{~m}$ for Case II-2).

In Case II-3, the water depth increases up to the midpoint of the crossing before rapidly decreasing, and falls to a level simi- lar to those in Cases II-1 and II-2 after passing the crossing. Although two hydraulic jumps are observed after the flow passes the crossing in channels (2) and (4) in Case I-3, smaller ones are found in channels (1) and (3) in Case II-3.

As the inflow increases in channels (2) and (4), the water depth in the crossing remains almost constant in Case II-1, but rapidly falls immediately before passing the crossing. In Cases II-2 and II-3, the water depth decreases before the flow reaches the crossing, and the surface profiles are convex-shaped in the crossing area. This phenomenon becomes increasingly evident when the inflow increases, and the water depth distribution following the flow movement through the crossing is almost consistent (1.5 cm for Case II-1, $3 \mathrm{~cm}$ for Case II-2, and $4.3 \mathrm{~cm}$ for Case II-3).

Table 6 shows the comparison of the maximum and minimum water depths in channels (1) and (3), and in channels (4) and (2) for Cases I and II. The results suggest that the maximum depth in channels (1) and (3) increases in Cases I-1 and I3 by two and three times, respectively, compared to Case I-1, and increases by a similar ratio in Case II. The maximum water depth in channels (4) and (2) increases in Cases I-2 and I-3 by 1.5 times and two times, respectively, compared to Case I-1, and increases by a similar ratio in Case II. The minimum water depth in channels (1) and (3) increases in Cases I-2 and I-3 by 1.1 times and 1.4 times, respectively, compared to Case I-1, but shows no significant change in Case II. The minimum depth in channels (2) and (4) increases in Cases I-2 and I-3 by 1.5 times and 2.1 times, respectively, compared to Case I-1, and increases in Cases II-2 and II- 3 by 2.2 times and 3.8 times, respectively, compared to Case II-1. 
Table 6. Comparison of maximum and minimum water depths for Case I and II.

\begin{tabular}{|c|c|c|c|c|}
\hline \multirow{2}{*}{ Case I- } & \multicolumn{2}{|c|}{ Along channels (1)-(3) } & \multicolumn{2}{|c|}{ Along channels (2)-(4) } \\
\hline & Max. water depth (m) & Min. water depth (m) & Max. water depth (m) & Min. water depth (m) \\
\hline 1 & 0.032 & 0.009 & 0.033 & 0.010 \\
\hline 2 & 0.049 & 0.010 & 0.050 & 0.015 \\
\hline 3 & 0.063 & 0.013 & 0.066 & 0.021 \\
\hline \multirow{2}{*}{ Case II- } & \multicolumn{2}{|c|}{ Along channels (1)-(3) } & \multicolumn{2}{|c|}{ Along channels (2)-(4) } \\
\hline & Max. water depth (m) & Min. water depth (m) & Max. water depth (m) & Min. water depth (m) \\
\hline 1 & 0.029 & 0.013 & 0.029 & 0.013 \\
\hline 2 & 0.047 & 0.013 & 0.046 & 0.028 \\
\hline 3 & 0.062 & 0.012 & 0.059 & 0.049 \\
\hline
\end{tabular}

\section{CONCLUSIONS}

In this study, the hydraulic-model experiment and the numerical simulation were performed in order to investigate the characteristics of water-surface in and around a crossing connected to channels aligned non-orthogonally, and the following results were obtained.

The experimental and numerical results of water depth distribution in the crossing with increasing inflows were in relatively good agreement.

When the same inflows entered two channels, the water depth in the horizontal channel (channels (1) and (3)) immediately decreased after the flow entered the crossing (Case I); however, the water depth before the flow arrived at the crossing remained constant, when either of the two channels had an increasing inflow, and decreased rapidly before the flow passed the crossing (Case II). In addition, while a clear hydraulic jump was observed with a rapidly increasing water depth after the flow passed the crossing in Case I, the water depth in Case II gradually increased, resulting in relatively smaller hydraulic jumps.

When the same quantity of water flowed into channels (2) and (4), the water depth rapidly decreased immediately after the flow reached the crossing. With increasing inflow, the water depth increased abruptly after the flow passes the crossing, producing increasingly large hydraulic jumps (Case I). In particular, two hydraulic jumps were observed in Case I-3. The water depth tended to be lower in Case II before the flow reached the crossing, and the surface profiles were convex shaped in the crossing area. This phenomenon was more evident when the inflow increased, and is associated with a consistent depth distribution after the flow passed the crossing.

The results of the hydraulic-model experiment and the numerical simulation of water flows at a channel crossing, where the channels are connected non-orthogonally at $45^{\circ}$ and $135^{\circ}$ have only limited applicability in terms of establishing flood prevention plans for urban areas. To resolve this limitation, it is necessary to perform hydraulic-model experiments and numerical analyses of structures having connecting channels with more diverse angles. Therefore, hydraulic-model experiments with connection angles of $22.5^{\circ}$ and $67.5^{\circ}$ are currently underway. In this study, the water-surface variations around the crossing were only investigated physically and numerically. In the further study, the water velocity fields in and around the crossing area will be considered.

Acknowledgement. This research was supported by the Basic Science Research Program through the National Research Foundation of Korea (NRF) funded by the Ministry of Education (2020R1D1B012688).
Conflicts of interest. The authors declare that they have no conflict-of-interest statements.

\section{REFERENCES}

Abderrezzak, K.E.K., Lewicki, L., Paquier, A., Rivière, N., Travin, G., 2011. Division of critical flow at three-branch open-channel intersection. Journal of Hydraulic Research, 49, 2, 231-238. https://doi.org/10.1080/00221686.2011.558174

Alamayreh, M.I., Fenocchi, A., Petaccia, G., Sibilla, S., Persi, E., 2021. Numerical analysis of fluid flow dynamics around a yawed half-submerged cylinder inside an open channel. Journal of Hydrodynamics, 33, 111-119. https://doi.org/10.1007/s42241-021-0005-0

ANSYS, 2013. CFX-solver theory guide. Release 13.0. ANSYS Inc.; 275 Technology Drive, Canonsburg, PA 15317, USA, 390 p.

Best, J.L., Reid, I., 1984. Separation zone at open-channel junctions. Journal of Hydraulic Engineering, 110, 1588-1594, https://doi.org/10.1061/(ASCE)0733-9429(1984)110:11(1588)

Bowers, C.E., 1966. Study of open channel junctions. Technical paper. Part V of Hydraulic model studies for Whiting Field Naval Air Station, 6, 1-250.

Ghostine, R., Kesserwani, G., Vazquez, J., Rivière, N., Chenaim, A., 2009. Simulation of supercritical flow in crossroads: Confrontation of a 2D and 3D numerical approaches to experimental results. Computational Fluids, 38, 425-432. https://doi.org/10.1016/j.compfluid.2008.05.003

Huang, J.C., Weber, L.J., Lai, Y.G., 2002. Three-dimensional numerical study of flows in open-channel junctions. Journal of Hydraulic Engineering. 128, 268-280, https://doi.org/10.1061/(ASCE)0733-9429(2002)128:3(268)

Jeong, W.C., Lee, J.W., Cho, Y.S., 2010. A numerical study on characteristics of flow in a crossroad: Case of crossroad connected symmetrically with inclined four roads. Journal of Korean Society of Hazard Mitigation, 10, 99-108.

Khan, A., Cadavid, R., Wang, S., 2000. Simulation of channel confluence and bifurcation using the CCHE2D model. P.I. Civil Eng-Water, 142, 97-102. https://doi.org/10.1680/wame.2000.142.2.97

Martinez, M., Niño, Y., 2020. 3D numerical modeling to support the design of contractions in supercritical flow channels. In: 8th IAHR ISHS 2020, Santiago, Chile, May 12-15 2020. https://doi.org/10.14264/uq1.2020.610

Matthews, B.W., Fletcher, C.A.J., Patridge, A.C., 1998. Computational simulation of fluid and dilute particulate flows on spiral concentrators. Applied Mathematical Modelling, 22, 12, 965-979. https://doi.org/10.1016/S0307-904X(98)10030-6

Mignot, E., 2005. Etude expérimental et numérique de l'inondation d'une zone urbanisée: Cas des écoulements dans les carrefours en croix. PhD Thesis. Ecole Centrale de Lyon, 
Lyon, France. (In French.)

Mignot, E., Paquier, A., Haider, S., 2006. Modeling floods in a dense urban area using 2D shallow water equations. Journal of Hydrology, 327, 186-199. https://doi.org/10.1016/j.jhydrol.2005.11.026

Mignot, E., Paquier, A., Rivière, N., 2008. Experimental and numerical modeling of symmetrical four-branch supercritical cross junction flow. Journal of Hydraulic Research, 46, 723738. https://doi.org/10.1080/00221686.2008.9521918

Mignot, E., Li, X., Dewals, B., 2019. Experimental modelling of urban flooding: A review. Journal of Hydrology, 568, 334-342. https://doi.org/10.1016/j.jhydrol.2018.11.001

Nania, L.S., Gomez, M., Dolz, J., 2004. Experimental study of the dividing flow in steep street crossings. Journal of Hydraulic Research, 42, 406-412. https://doi.org/10.1080/00221686.2004.9728406

Neary, V., Sotiropoulos, F., Odgaard, A., 1999. Threedimensional numerical model of lateral-intake inflows. Journal of Hydraulic Engineering, 125, 126-140. https://doi.org/10.1061/(ASCE)0733-9429(1999)125:2(126)

Paquier, A., 1995. Modélisation et simulation de la propagation de l'onde de rupture de barrage. Ph.D. Thesis. Université Jean Monnet de Saint Etienne, Saint Etienne, France, 340 p.

Rivière, N., Perkins, R.J., 2004. Supercritical flow in channel intersections. In: Grecco, Carravetta, Della Morte (Eds.): Proceedings of the 2nd International Conference on Fluvial Hydraulics "River Flow 2004". Napoli, Italy, 23-25 June 2004, pp. 1073-1077. https://doi.org/10.1201/b16998-138
Rivière, N., Travin, G., Perkins, R.J., 2011. Subcritical channel open flows in four branch intersections. Water Resources Research, 47, W10517. https://doi.org/10.1029/2011WR010504

Rivière, N., Travin, G., Perkins, R.J., 2014. Subcritical open channel flows in four branch intersections, Journal of Hydraulic Engineering, 140, 4, 04014003. https://doi.org/10.1061/(ASCE)HY.1943-7900.0000835

Schwalt, M., Hager, W.H., 1995. Experiments to supercritical junction flow. Experiments in Fluids, 18, 429-437. https://doi.org/10.1007/BF00208465

Shetter, A.S., Murthy, K.K., 1996. A numerical study of division of flow in open channels. Journal of Hydraulic Research. 34, 651-675. https://doi.org/10.1080/00221689609498464

Shumate, E.D., 1998. Experimental description of combining flows at an open channel junction. Master Thesis. University of Iowa, Iowa, USA, 127 p.

Thappeta, S.K., Bhallamudi, S.M., Chandra, V., Fiener, P., Baki, A.B.M., 2021. Energy loss in steep open channels with step-pools. Water, 13, 1, 72, 1-21. https://scihub.do/https://doi.org/10.3390/w13010072

Weber, L.J., Schumate, E.D., Mawer, N., 2001. Experiment on flow at a $90^{\circ}$ open-channel junction. J. Hydraul. Eng., 127, 340-350. https://doi.org/10.1061/(ASCE)07339429(2001)127:5(340)

Received 3 January 2021 Accepted 9 April 2021 